\title{
Papers
}

\section{Incidence of malaria among children living near dams in northern Ethiopia: community based incidence survey}

\author{
Tedros A Ghebreyesus, Mitiku Haile, Karen H Witten, Asefaw Getachew, Ambachew M Yohannes, \\ Mekonnen Yohannes, Hailay D Teklehaimanot, Steven W Lindsay, Peter Byass
}

\begin{abstract}
Objective To assess the impact of construction of microdams on the incidence of malaria in nearby communities in terms of possibly increasing peak incidence and prolonging transmission.

Design Four quarterly cycles of malaria incidence surveys, each taking 30 days, undertaken in eight at risk communities close to dams paired with eight control villages at similar altitudes but beyond flight range of mosquitoes.

Setting Tigray region in northern Ethiopia at altitudes of 1800 to $2225 \mathrm{~m}$.

Subjects About 7000 children under 10 years living in villages within $3 \mathrm{~km}$ of microdams and in control villages $8-10 \mathrm{~km}$ distant.

Main outcome measures Incidence of malaria in both communities.

Results Overall incidence of malaria for the villages close to dams was 14.0 episodes/1000 child months at risk compared with 1.9 in the control villages-a sevenfold ratio. Incidence was significantly higher in both communities at altitudes below $1900 \mathrm{~m}$.

Conclusions There is a need for attention to be given to health issues in the implementation of ecological and environmental development programmes, specifically for appropriate malaria control measures to counteract the increased risks near these dams.
\end{abstract}

\section{Introduction}

In 1974 and 1984 severe famines occurred in Ethiopia, attributable to drought, erratic rainfall, and dependence on traditional rainfed agriculture coupled with many years of war. Tigray region in northern Ethiopia with a population of 3.2 million, of whom $85 \%$ live in rural areas, was one of the worst affected.

To deal with these problems the regional government of Tigray initiated a postwar rural development programme called "Sustainable Agricultural and Environmental Rehabilitation in Tigray" (SAERT), the main objective of which was to minimise dependence on rainfed agriculture and improve food production by constructing microdams and introducing irrigation systems.

Alongside potential advantages of increased agricultural productivity, development of water resources may have both positive and negative impacts on health. ${ }^{1-3}$ Diseases that rely on the presence of water for transmission-such as malaria and schistosomiasis-may increase in incidence. As a result of such large scale development in Sri Lanka, malaria became prevalent in areas where it was once declared to have been nearly eradicated. ${ }^{4}$ In the Rusizi valley, Burundi, parasite prevalence rates were substantially higher than outside the irrigation scheme, ${ }^{5}$ and in Sudan transmission changed from a seasonal to a perennial pattern in irrigated areas. ${ }^{6}$ Cross sectional pilot studies in Tigray suggested that malaria was more prevalent in villages close to existing microdams compared with villages where dams were not yet built. ${ }^{78}$

In Tigray region, malaria follows a highland, hypoendemic pattern with seasonal transmission, mainly from September to November, after rain from June to August. Of the entire population, $60 \%$ live in malarious areas, and malaria is a major public health problem, being a significant cause of morbidity and mortality. As the overall incidence of malaria is modest in this highland area, acquired immunity also tends to be low and so epidemics can be serious. The major vector is Anopheles arabiensis, and around $90 \%$ of infections in the high transmission season are Plasmodium falciparum. Extrapolations from studies of malaria and irrigation in other environments are therefore tenuous, particularly for variations specific to altitude and season. Against this background, possible effects of the current water resources development programme on malaria in Tigray have been investigated in a 1 year longitudinal study, which examined whether dams increase the risk of malaria in established hypoendemic situations, extend established seasonal patterns of malaria transmission, and facilitate transmission of malaria at altitudes otherwise free from the disease.

\section{Methods}

Eight microdams in the Tigray region (in rural areas, with established permanent water) were identified, at altitudes of $1800 \mathrm{~m}$ to $2225 \mathrm{~m}$. By using established data on the flight patterns of anopheline mosquitoes ${ }^{9} 10$ rural communities within $3 \mathrm{~km}$ of the dams were identified as potentially at risk, and villages at a similar altitude (within $200 \mathrm{~m}$ ) and 8 to $10 \mathrm{~km}$ from the dams were randomly identified as controls. Villages within $8 \mathrm{~km}$ of other major water bodies (impounded water

\author{
Editorial by \\ Brewster \\ Tigray Regional \\ Health Bureau, \\ Department of \\ Malaria Control, \\ Mekelle, Ethiopia \\ Tedros A \\ Ghebreyesus \\ Karen H Witten \\ epidemiologist \\ Asefaw Getachew \\ entomologist \\ Ambachew M \\ Yohannes \\ medical parasitologist \\ Hailay D \\ Teklehaimanot \\ epidemiologist \\ Mekelle University \\ College, Mekelle, \\ Ethiopia \\ Mitiku Haile \\ dean \\ Mekonnen \\ Yohannes \\ lecturer \\ Department of \\ Biological Sciences, \\ University of \\ Durham, Durham \\ DH1 3LE \\ Steven W Lindsay \\ reader \\ School of \\ Community Health \\ Sciences, University \\ of Nottingham, \\ Nottingham \\ NG13 8FD \\ Peter Byass \\ senior lecturer \\ Correspondence to: \\ TA Ghebreyesus \\ witten@telecom.net.et
}

BMJ 1999;319:663-6 
persisting perennially) or which had been spray treated were excluded from further consideration. To monitor the incidence of malaria in the community longitudinally four surveys were planned in a 1 year period among children under 10 years of age. The study was designed to detect a 1.33 relative rate of incidence of $P$ falciparum malaria (20\% in the at risk group and $15 \%$ in the control group) with a drop out rate of $20 \%$ and a design factor of 3 (to allow for the dam effect operating at village rather than individual level) with $80 \%$ power and $95 \%$ confidence, leading to a total requirement of almost 7000 children. House to house census surveys were undertaken in identified at risk and control communities, giving rise to slightly over 7000 children under 10 years of age (age determined by interview with parents or guardians); no further sampling was therefore required. The census data were entered on a dBase computerised system that enabled tracking of individuals and vital events throughout the survey. ${ }^{11}$ The mean altitude of the at risk communities was $2013 \mathrm{~m}$ and of the control communities $1991 \mathrm{~m}$, while the dams themselves were situated at similar altitudes to the corresponding communities (mean $1997 \mathrm{~m}$ ).

Field work was undertaken by enumerators specifically recruited and trained, both at headquarters and on site. Each quarterly survey was undertaken in two phases. Firstly, blood films were sought from all children under 10 years, and those with clinical malaria (defined as 1 or more days of fever, chills, sweating, headache) were treated with chloroquine $(25 \mathrm{mg} / \mathrm{kg}$ over 3 days) and another blood film taken after 14 days. Secondly, further blood films were sought from all children as close to 30 days as possible after their initial film. Overall compliance with blood taking was $93 \%$ in both groups. During the intervening period any child falling sick was encouraged to consult the project enumerator in their village for passive case detection, at which time a further blood film was taken and chloroquine given if appropriate. Surveys were conducted on this basis simultaneously in all villages four times during 1997: in January-February, April-May, July-August, and October-November. All blood films were initially read in local malaria control laboratories. Films positive for parasites and a 10\% sample of films negative for parasites were subsequently checked in the regional office; when discrepancies remained, a third independent reading was made and the majority opinion taken.

Incidence of malaria by season and altitude for children under 10 years in highland Ethiopia in at risk communities (close to dams) and control communities (away from dams)

\begin{tabular}{|c|c|c|c|c|c|}
\hline \multirow{2}{*}{$\begin{array}{l}\text { Altitude and } \\
\text { season }\end{array}$} & \multicolumn{2}{|c|}{ At risk } & \multicolumn{2}{|c|}{ Control } & \multirow{2}{*}{$\begin{array}{l}\text { Rate ratio }(95 \% \mathrm{Cl}) \text { for } \\
\text { comparison group }\end{array}$} \\
\hline & Cases* & Incidence (\%) & Cases* & Incidence (\%) & \\
\hline \multicolumn{6}{|c|}{1800 to $1899 \mathrm{~m}$} \\
\hline Jan-Feb & $7 / 390$ & 17.9 & $2 / 279$ & 7.2 & 2.5 (0.52 to 12.1$)$ \\
\hline Apr-May & $19 / 449$ & 42.3 & $2 / 330$ & 6.1 & 6.98 (1.63 to 30.0$)$ \\
\hline Jul-Aug & $33 / 460$ & 71.7 & $1 / 293$ & 3.4 & $21.0(2.87$ to 153$)$ \\
\hline Oct-Nov & $43 / 384$ & 111.9 & $3 / 249$ & 12.0 & $9.29(2.88$ to 30.0$)$ \\
\hline \multicolumn{6}{|c|}{1900 to $2225 \mathrm{~m}$} \\
\hline Jan-Feb & $6 / 2522$ & 2.4 & $4 / 2771$ & 1.8 & $1.65(0.46$ to 5.84$)$ \\
\hline Apr-May & $7 / 2568$ & 2.7 & $1 / 2846$ & 0.4 & $7.76(0.95$ to 63.1$)$ \\
\hline Jul-Aug & $2 / 2527$ & 0.8 & $2 / 2720$ & 0.7 & 1.08 (0.15 to 8.39$)$ \\
\hline Oct-Nov & $43 / 2092$ & 20.6 & $6 / 2450$ & 2.4 & 8.39 (3.57 to 19.7$)$ \\
\hline
\end{tabular}

*Per child months at risk.

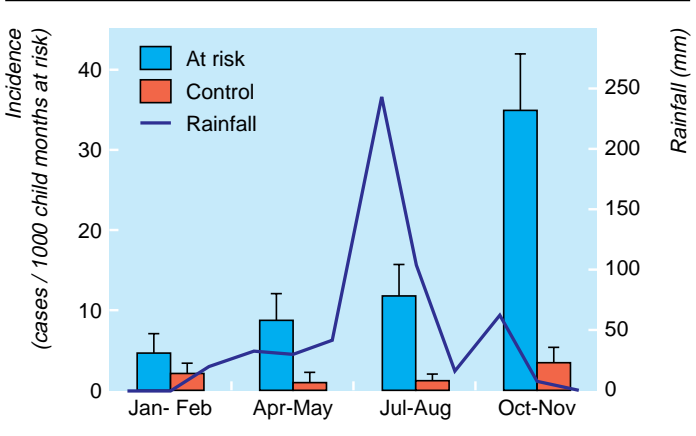

Incidence of malaria (with 95\% confidence intervals) among children under 10 years in highland Ethiopia in at risk communities (close to dams) and control communities (away from dams) during 1997 and rainfall, which governs the seasonal pattern of malaria in this environment

The computer system at the regional headquarters was used to facilitate longitudinal monitoring of the surveyed population and to process the results of blood films. ${ }^{11}$ Days at risk were calculated in untreated children from date of first film to date of passive case detection (if treated or positive) or date of second film, and days at risk for treated children were similarly calculated from time of negative follow up film to passive case detection or second film. Children whose first film yielded positive results for $P$ falciparum were excluded even if results were negative on follow up (14 days) as late recrudescence could not be ruled out. ${ }^{12}$ As children with $P$ vivax infections were not treated with primaquine, relapsing vivax infections could not be ruled out; thus second and subsequent $P$ vivax infections in individual children were not taken as incident cases. Incidence rates were calculated from numbers of incident cases and child months at risk, the latter being calculated on a daily individual basis from the database system.

Statistical analyses of incidence are based on rates of cases per child month at risk, with 95\% confidence intervals of incidence rates and rate ratios when appropriate. ${ }^{13}$

Ethical approval for this study was given by the Ethiopian Science and Technology Commission and the Tigray Regional Health Bureau and local consent obtained through community meetings.

\section{Results}

Over the 1 year period of surveillance 160 incident cases were detected in at risk communities during 11392 child months at risk, giving a rate of 14.0 episodes/1000. For control villages, 23 cases in 11938 child months gave 1.9 episodes $/ 1000$, giving a 7.3 -fold increased incidence close to dams. This is a highly significant difference, with a $95 \%$ confidence interval of 4.7 to 11.3 . Of the total 183 cases, 107 were diagnosed as $P$ falciparum, 73 as $P$ vivax, and three as mixed. The proportion of $P$ vivax infections was not significantly different between at risk and control groups. Six children experienced second $P$ vivax episodes, which were excluded.

The seasonal variations in incidence are shown in the figure, together with rainfall patterns. The overall results are presented stratified by altitude and season in 
the table. For the dams below $1900 \mathrm{~m}$ the overall incidence for the year in at risk communities was 60.6 episodes/1000 child months at risk compared with 7.0 in controls; a rate ratio of 8.7 (95\% confidence interval 4.2 to 17.9). Similarly for the higher dams overall rates were 6.0 and 1.2; rate ratio 5.0 (2.7 to 9.0). The difference in incidence between the two altitude bands was significant for the at risk communities (rate ratio $10.1 ; 7.3$ to 14.0$)$ and the control communities $(5.8 ; 2.4$ to 13.9). In two high altitude dams (2100 and $2225 \mathrm{~m}$ ) no cases were detected in either at risk or control populations from a total of 7388 child months at risk.

\section{Discussion}

It seems clear from these results that microdams close to villages have the potential to increase the incidence of malaria substantially among children living nearby. Malaria at all of these study sites is hypoendemic as they are at altitudes where malaria transmission is marginal. The effect of altitude on incidence is clearly important; our results suggest an appreciably greater amount of malaria in villages near dams at altitudes below $1900 \mathrm{~m}$ than above. At both altitudes, however, there was also a similar difference between at risk and control communities, suggesting that the dams affect different intensities of existing transmission. The seasonal pattern of incidence in both at risk and control communities generally follows the rainfall pattern, as shown in the figure, with the peak incidence slightly later than the peak rainfall. In April to May, when transmission would be expected to be at its lowest, the incidence ratio between at risk and control communities was similar to that in the peak transmission season, suggesting that the dams are increasing established patterns of transmission throughout the year. This is important because it leads to greatly increased levels of malaria at the end of the transmission season, as seen in other areas of low exposure to $P$ falciparum. ${ }^{14}$ The observation of no cases in either group at two of the higher dams, however, does not support the possibility that dams might facilitate transmission in areas otherwise free from malaria

Malaria is probably the major threat to health and life in Africa and so any increased risk has to be considered carefully. In this case, compared with many locations in Africa, the risk is still moderate- even near dams only around $16 \%$ of children might be expected to be infected each year. On the other hand, these villages generally consist of children who have not been continually challenged by the disease from infancy and who are therefore unlikely to have developed protective immunity. The dams thus represent a risk of serious illness or death to children in these communities. This can reasonably be extrapolated in terms of economic loss and also risk to older members of the community, who are also not immune or only partly so. Effective malaria control strategies therefore need to be implemented in communities exposed to these risks.

Our findings also raise serious concerns about the potential effects of ecological and agricultural development on public health. While in the light of past severe droughts in this region the need to conserve and store water is crucial for human life, animal husbandry, and agriculture, we have shown that an obvious solution such as the construction of dams may also have
Key messages

- Environmental development may have important effects on the epidemiology of vector borne diseases such as malaria

- This may be particularly important where disease transmission is unstable-for example, in highland areas

- Children in villages near recently constructed microdams in northern Ethiopia had a significantly increased risk of malaria

- It seems that this irrigation development programme is leading to increased malaria transmission across a range of altitudes and seasons

- Intersectoral collaboration is necessary in development projects that may affect communities both positively and negatively

unforeseen detrimental effects. Many more dams are planned in the Tigray region. These plans will need to be carefully reviewed in the light of our findings so that, when possible, future dams will be sited at the highest feasible altitudes and as far away as possible from villages.

In the next phase of our research we plan to offer bednets to villagers living close to existing dams to test the hypothesis that using bednets can counteract the increased risks associated with the dams. At the same time the economic benefits of the dams will be assessed and compared with the cost of bednets. Bednets will be provided under a revolving fund, cost recovery basis and the sustainability of this evaluated. The effects of these dams on schistosomiasis is also being investigated.

The importance of continuing intersectoral collaboration in assessing the health impact of the dam programme and in working together to maximise the benefits of the dams while also minimising the risks is clearly crucial. The community based malaria control programme already in place ${ }^{15}$ and the strong commitment shown by the regional government are important elements in this endeavour. This is also an important principle for similar development programmes elsewhere.

We are grateful for the contributions made by Hellen Ohlin at SIDA/SAREC, support staff at the institutions involved, the village based enumerators, and the villagers who agreed to participate. Further background information is available at www.members.aol.com/peterbyass/tigray/index.html

Funding: This project was funded by SIDA/SAREC, Sweden, and supported by the UNDP/World Bank/WHO Special Programme for Research and Training in Tropical Diseases (TDR).

Competing interests: None declared.

Contributors: TAG participated in the design and analysis, led the study, and cowrote the paper. MH conceived the study and supervised throughout. KHW participated in design, field work, analysis, and contributed to the manuscript. AG, AMY, MY, and HDT were responsible for the implementation and supervision of field work. SWL advised on project design and implementation. PB advised on design and implementation and cowrote the paper. $\mathrm{MH}$ and $\mathrm{PB}$ are guarantors for the study.

1 Bradley DJ. The epidemiology of ricefield-associated diseases. In International Rice Research Institute in collaboration with WHO/FAO/ UNEP, Panel of Experts on Environmental Management for Vector 
Control. Vector-borne disease control in humans through rice agroecosystems management. Philippines: International Rice Research Institute, 1988:29-39.

2 Gratz NG. The impact of rice production on vector-borne disease problems in developing countries. In: International Rice Research Institute in collaboration with WHO/FAO/UNEP, Panel of Experts on Environmental Management for Vector Control. Vector-borne disease control in humans agroecosystems management. Philip in stitute, 1988:7-12.

3 Hunter JM, Rey L, Chu KY, Adekolu-John EO, Mott KE. Parasitic diseases in water resources development. The need for intersectoral negotiation. World Health Organisation: Geneva, 1993.

4 Ramasamy R, de Alwis R, Wjesundere A, Ramasamy S. Malaria transmission at a new irrigation project in Sri Lanka: the emergence of Anopheles annularis as a major vector. Am J Trop Med Hyg 1992; 47:547-53.

5 Coosemans M, Wery M, Storme B, Hendrix L, Mfisi B. Epidemiologie du paludisme dans la plaine de la Rusizi, Burundi. Ann Soc Belge Med Trop 1984;64:135-58

6 El Gaddal AA, Haridi AAM, Hassan FT, Hussein H. Malaria control in the Gezira-Managil irrigated scheme of the Sudan. J Trop Med Hyg 1985;88:153-9.

7 Ghebreyesus TA, Haile M, Getachew A, Alemayehu T, Witten KH, Medhin A, et al. Pilot studies on the possible effects on malaria of smallscale irrigation dams in Tigray Regional State, Ethiopia. J Pub Health Med 1998;20:238-40.
8 Alemayehu T, Ye-ebiyo Y, Ghebreyesus TA, Witten KH, Bosman A, Teklehaimanot A. Malaria, schistosomiasis, and intestinal parasites in relation to microdams in Tigray, Northern Ethiopia. Parassitologia 1998;40: 259-67.

9 Gillies MT. Anopheline mosquitoes: vector behaviour and bionomics. In: Wernsdorfer WH, McGregor I, eds. Malaria: principles and practice of malariology. Vol 1. London: Churchill Livingstone, 1988:453-85.

10 De Meillon B. The anophelini of the Ethiopian geographical region. Publications of the South African Institute for Medical Research 1947;10:190-203.

11 Stephens J, Alonso PL, Byass P, Snow RW. Tropical epidemiology: a system for continuous demographic monitoring of a study population. Meth Inform Med 1989;28:155-9.

12 Teklehaimanot A. Chloroquine-resistant Plasmodium falciparum in Ethiopia. Lancet 1986;ii:127-9.

13 Kirkwood B. Essentials of medical statistics. Oxford: Blackwell Scientific, 1988:129-30.

14 Bouma MJ, Sondorp HE, Van der Kaay HJ. Climate change and periodic epidemic malaria. Lancet 1994;343:302.

15 Ghebreyesus TA, Alemayehu T, Bosman A, Witten KH, Teklehaimanot A. Community participation in malaria control in Tigray region Ethiopia. Acta Tropica 1996;61:145-56.

(Accepted 2 June 1999)

\title{
Cirrhosis mortality and per capita consumption of distilled spirits, United States, 1949-94: trend analysis
}

\author{
Ron Roizen, William C Kerr, Kaye M Fillmore
}

University of

California, San

Francisco,

Department of

Social and

Behavioral Sciences

Box 0612, San

Francisco, CA

94143-0612, USA

Ron Roizen

specialist sociologist

William C Kerr

assistant research

economist

Kaye M Fillmore

professor

Correspondence to:

R Roizen

ron@roizen.com

BMJ 1999;319:666-70

website

extra

Additional

information is

available on the

BMJ's website

www.bmj.com

\begin{abstract}
Objective To describe, evaluate, and suggest interpretations for an observed aggregate level relation between trends in mortality from cirrhosis and per capita consumption of distilled spirits in the United States.

Design Trend analysis using data on US cirrhosis mortality and per capita alcohol consumption.

Results There is a consistent long term trend relation between mortality from cirrhosis and per capita consumption of distilled spirits in the United States from 1949 to 1994. Two instances of comparatively sharp drops in the consumption of spirits earlier in the 1940s generated mixed results in predicting changes in cirrhosis mortality.

Conclusions An aggregate level relation between trends in long term cirrhosis mortality and the consumption of spirits falls considerably short of establishing a direct causal link between the two for individuals. Moreover, two sharp drops in the consumption of spirits generated only mixed results with respect to the short term trend in cirrhosis. Nevertheless, the observed relation between the consumption of spirits and cirrhosis mortality merits further investigation.
\end{abstract}

\section{Introduction}

This paper presents new epidemiological evidence of an aggregate level relation between trends in per capita consumption of distilled spirits and death from cirrhosis in the United States. Such data may help to understand why a long rise in the trend of deaths from cirrhosis after the second world war unexpectedly fell after 1973 even as the trend in total per capita consumption of alcohol continued to rise until the early 1980s. Although evidence of an aggregate level correlation between the consumption of spirits and death from cirrhosis falls short of showing a direct or causal relation between the use of spirits and the risk of cirrhosis for individuals, it suggests that there is value in pursuing further multidisciplinary investigations to discern the links between the consumption of specific alcoholic beverages and cirrhosis.

Mortality from cirrhosis in the United States rose by $75 \%$ from 1950 to 1973 (from 8.5 to 14.9 deaths per 100000 population), accounting for 33350 deaths in the peak year of 1973. After this time, cirrhosis mortality began a long, slow decline, falling to 7.9 deaths per 100000 by 1993, roughly half of the 1973 rate and marginally below the rate in 1950 (fig 1a). The reasons why cirrhosis mortality fell and why the fall started when it did are unclear. A large fraction of cirrhosis mortality has long been associated in both medical and popular thinking with heavy drinking. ${ }^{2}$ Do changes in American drinking practices account for changes in the trend? Per capita alcohol use also rose and then fell during the period after the second world war, increasing by $38 \%$ from the late 1950 s to 1980 (from a mean of 7.57 litres of absolute alcohol to 10.45 litres for the drinking age population) and then falling by $20 \%$ from the early 1980 s to the mid-1990s (to 8.36 litres) (fig 1a). However, the order of the peaks in time in the two trends is contrary to what would have been expected if the fall in alcohol consumption had caused the fall in cirrhosis mortality. The beginning of the decline in cirrhosis mortality in the mid-1970s preceded the beginning of the decline in consumption by seven or eight years, thus generating a transitional period (1973-80) when cirrhosis mortality was falling but per capita alcohol consumption was still rising.

Alcohol consumption should not, therefore, be eliminated as a possible explanation for the decline in cirrhosis mortality that occurred after 1973 in the 